\title{
PENGEMBANGAN MEDIA PEMBELAJARAN BERBASIS VIDEOSCRIBE SPARKOL PADA MATERI KEKONGRUENAN DAN KESEBANGUNAN DI SMP PGRI 2 BOGOR
}

\author{
Ardistya Puspita Sari*1, Indra Martha Rusmana ${ }^{2}$ \\ ${ }^{1}$ SMP PGRI 2 Bogor, ${ }^{2}$ Universitas Indraprasta PGRI \\ ardistyaps@gmail.com ${ }^{* 1}$, indramartharusmana@ymail.com²
}

\begin{abstract}
This study aims to determine the feasibility of using learning media based on Videoscribe Sparkol on congruence and similarity material at SMP PGRI 2 Bogor. The method used in this study is the Research and Development method using ADDIE development procedures, namely (Analysis, Design, Development, Implementation, and Evaluation). The data collection method used an expert test validation questionnaire. The results of data analysis in the media validation process included media experts, namely 4.00 meaning "good", material experts, namely 4.00 intention "good", and development experts, namely 4.25 meaning "very good". It can be concluded that the average feasibility of learning media based on Sparkol videoscribe is feasible because the intermediate results are promising. This media development was carried out until expert testing and was not carried out in the field due to the Covid-19 pandemic in 2020.
\end{abstract}

Keywords: ADDIE Model, Videoscribe Media, Congruence and Similarity

\begin{abstract}
Abstrak
Penelitian ini bertujuan untuk mengetahui kelayakan penggunaan media pembelajaran berbasis Videoscribe Sparkol pada materi kekongruenan dan kesebangunan di SMP PGRI 2 Bogor. Metode yang digunakan penelitian ini adalah metode Research and Development (Penelitian Pengembangan) dengan menggunakan prosedur pengembangan ADDIE yaitu (Analysis, Design, Development, Implementation, and Evaluation). Metode pengambilan data menggunakan angket validasi uji pakar. Hasil analisis data dalam proses validasi media diantaranya dari ahli media yaitu 4,00 berarti "baik", ahli materi yaitu 4,00 berarti "sbaik" dan ahli pengembangan yaitu 4,25 berarti "Sangat baik". Dapat disimpulkan bahwa ratarata kelayakan media pembelajaran berbasis videoscribe sparkol adalah layak karena rata-rata menunjukkan hasilnya adalah baik. Pengembangan media ini dilakukan sampai uji pakar saja dan tidak dilakukan uji lapangan karena pandemi covid-19 tahun 2020.
\end{abstract}

Kata kunci: Model ADDIE, Media Videoscribe, Kekongruenan dan kesebangunan 
Jurnal Lebesgue : Jurnal Ilmiah Pendidikan Matematika, Matematika dan Statistika

Ardistya Puspita Sari, Indra Martha Rusmana

Volume 2, No. 1, April 2021 hal.112-120

DOI Artikel : 10.46306/lb.v2i1.29

\section{PENDAHULUAN}

Pendidikan merupakan suatu kebutuhan manusia yang sangat penting karena pendidikan memiliki tugas untuk menyiapkan sumber daya manusia bagi pembangunan bangsa dan negara. Menurut Heriyati (2017) berpendapat bahwa pendidikan mempunyai peranan yang sangat menentukan bagi perkembangan dan perwujudan diri individu terutama bagi pembangunan bangsa dan negara. Dengan pendidikan, manusia dapat mengerti, memahami dan secara aktif dapat mengembangkan potensi yang dimilikinya sehingga dapat memajukan kehidupannya.

Matematika merupakan salah satu ilmu yang sangat penting dalam kehidupan, karena matematika adalah salah satu aspek yangg mempengaruhi perkembangan dalam berbagai bidang. Menurut Achdiyat \& Utomo (2017) matematika menjadi faktor yang sangat penting berkaitan dengan sukses seseorang. Oleh sebab itu, matematika perlu dipelajari siswa sejak dari sekolah dasar sampai ke perguruan tinggi. Sebagai suatu ilmu pengetahuan, matematika bertujuan melatih manusia berfikir logis, kritis, dan bertanggung jawab. Memandang arti penting matematika, maka sudah selayaknya jika setiap siswa harus memiliki kemampuan untuk menguasai matematika. Matematika memiliki peran yang penting bagi perkembangan ilmu-ilmu lain. Selain itu matematika juga berfungsi sebagai alat yang dapat mengembangkan pola pikir, sehingga matematika merupakan salah satu mata pelajaran yang sangat penting dalam dunia pendidikan. Sebagai salah satu mata pelajaran yang sangat penting untuk dipelajari maka pembelajaran matematika harus dikemas dengan menarik agar mampu menumbuhkan minat belajar siswa. Materi matematika yang begitu banyak membuat siswa malas mencatat dan bosan jika harus mendengarkan guru ceramah. Oleh karena itu, penting bagi guru membekali siswa dengan media pembelajaran yang tidak hanya menarik namun juga dapat diakses dan dipelajari di rumah, agar siswa memiliki minat belajar yang tinggi.

Indonesia masih berada dominan di dalam level rendah, atau lebih pada kemampuan menghafal dalam pembelajaran sains dan matematika. Hal itu berdasarkan hasil Trends in Mathematics and Science Study (TIMSS) yang diikuti oleh siswa kelas VIII Indonesia tahun 2011 dimana Indonesia berada pada urutan ke-38 dari 42 negara yang dimuat dalam berita Kompas 14 Desember 2012. Kemudian berdasarkan berita di Kompas pula pada tanggal 11 Desember 2013, Indonesia masih tetap menduduki peringkat ke-2 dari bawah di antara 65 peserta pada Programme for International Student Assessment (PISA) yang mengikuti penilaian internasional di bidang matematika, membaca, dan sains. Kemudian Hal ini dikuatkan oleh Nizam (2016) juga dengan hasil Trends in Mathematics and Science Study (TIMSS) 2015 indonesia berada di peringkat 44 dari 49 negara. Berdasarkan hal ini dapat dilihat kemampuan 
Indonesia berdasarkan Survei Trends in Mathematics and Science Study (TIMSS) 2015 lebih ke arah tingkat rendah.

Pembelajaran yang biasanya digunakan di SMP PGRI 2 Bogor adalah metode ceramah dimana guru menjelaskan materi dan siswa mendengarkan lalu mencatat materinya. Namun masih ada beberapa siswa yang tidak memperhatikan pelajaran karena merasa bosan dengan penjelasan yang diberikan apalagi jika pembelajarannya kurang menarik mengakibatkan peserta didik cenderung tidak termotivasi dan tidak fokus dalam mengikuti pembelajaran yang pada akhirnya peserta didik sulit untuk memahami materi. Pembelajaran yang demikian merupakan pembelajaran yang kurang efektif sehingga tujuan pembelajaran akan sulit dicapai dikarenakan tidak semua siswa memperhatikan apa yang disampaikan oleh guru. Menurut Nurrohmah, dkk (2018) Perlu adanya pengembangan dalam media pembelajaran. Dengan adanya media pembelajaran yang interaktif dapat meningkatkan motivasi peserta didik dalam memahami pembelajaran matematika.

Di era modern ini, sangat tepat jika disediakan media pembelajaran yang sesuai dengan kemajuan Ilmu Pengetahuan dan Teknologi (IPTEK). Karena pada dasarnya generasi yang sekarang adalah generasi yang tidak lepas dari perkembangan teknologi. Anak zaman sekarang merupakan generasi yang dalam proses belajarnya nyaman dengan menggunakan peralatan digital. Untuk menyikapi hal seperti ini, maka media pembelajaran yang tepat untuk anak zaman sekarang adalah media pembelajaran yang berbasis digital. Salah satunya yakni media pembelajaran menggunakan Animasi. Media pembelajaran animasi dapat membuat siswa tertarik dengan apa yang disampaikan oleh guru. Media Pembelajaran Animasi salah satunya yang dapat dicoba oleh guru adalah Sparkol Videoscribe.

Sparkol Videoscribe merupakan sebuah media pembelajaran video animasi yang terdiri dari rangkaian gambar yang disusun menjadi sebuah video utuh. Dengan karakteristik yang unik, sparkol video scribe mampu menyajikan konten pembelajaran dengan memadukan gambar, suara, dan desain yang menarik sehingga siswa mampu menikmati proses pembelajaran. Fitur yang disediakan oleh software ini sangat beragam sehingga mampu menjadi media pembelajaran yang dapat disesuikan dengan mata pelajaran yang diinginkan. Selain dapat menggunakan desain yang telah disediakan di dalam software, pengguna dapat membuat desain animasi, grafis, maupun gambar yang sesuai dengan kebutuhan. Selain itu, pengguna juga dapat melakukan dubbing dan memasukkan suara sesuai kebutuhan 
Jurnal Lebesgue : Jurnal Ilmiah Pendidikan Matematika, Matematika dan Statistika

Ardistya Puspita Sari, Indra Martha Rusmana

Volume 2, No. 1, April 2021 hal.112-120

DOI Artikel : 10.46306/lb.v2i1.29

untuk membuat video. Pembuatan videoscribe juga dapat dilakukan secara offline sehingga tidak tergantung pada layanan internet, hal ini pastinya akan lebih memudahkan guru dalam membuat media pembelajaran menggunakan sparkol videoscribe.

Pemanfaatan teknologi untuk media pembelajaran diharapkan dapat menjadi suatu pembaharuan di dunia pendidikan. Media pembelajaran berbasis sparkol videoscribe ini juga dapat digunakan oleh siswa kapanpun dan dimanapun sehingga dapat membantu proses pembelajaran. Berdasarkan permasalahan di atas, penulis tertarik melakukan penelitian dengan judul "Pengembangan Media Pembelajaran Matematika Berbasis Videoscribe Sparkol pada Materi Kekongruenan dan Kesebangunan di SMP PGRI 2 Bogor”.

\section{METODE PENELITIAN}

Metode yang digunakan dalam penelitian ini adalah metode Penelitian dan Pengembangan (research and development). Untuk dapat mengembangkan media pembelajaran dapat menggunakan modern desain sistem pembelajaran, ADDIE (Analysis Design Develop Implementation Evaluate) yang dipadukan menurut langkah-langkah penelitian pengembangan yang direkomendasikan oleh Brog dan Gall dengan dasar pertimbangan bahwa model tersebut cocok untuk mengembangkan produk model intruksional/pembelajaran yang tepat sasaran, efektif, dan dinamis, dan sangat membantu dalam pengembangan pembelajaran bagi guru. Model desain intruksional ADDIE yang dikembangkan oleh Reiser dan Mollenda (1990-an) merupakan model desain pembelajaran/pelatihan yang bersifat generic menjadi pedoman dalam membangun perangkat dan infrastruktur program pelatihan yang efektif, dinamis dan mendukung kinerja pelatihan itu sendiri. Sehingga membantu intruktur pelatihan dalam pengelolaan pelatihan dan pembelajaran.

\section{HASIL DAN PEMBAHASAN}

\section{Analysis (Analisis Kebutuhan)}

Berdasarkan analisis kebutuhan melalui wawancara dengan guru matematika kelas 9 di SMP PGRI 2 Bogor bahwa rata-rata guru di SMP PGRI 2 Bogor masih menggunakan power point sebagai media yang digunakan dalam pembelajaran matematika. Ada pula guru yang mengatakan bahwa media pembelajaran harus selalu mengikuti perkembangan jaman yang ada agar tidak tertinggal dan dapat selalu menyesuaikan. Guru sangat mengharapkan media pembelajaran ini nantinya memiliki bahasa yang mudah dimengerti siswa dan tidak berbelit-belit, harus sesuai alur dan konsep yang benar. 
Jurnal Lebesgue : Jurnal Ilmiah Pendidikan Matematika, Matematika dan Statistika

Ardistya Puspita Sari, Indra Martha Rusmana

Volume 2, No. 1, April 2021 hal.112-120

DOI Artikel : 10.46306/lb.v2i1.29

Selain itu siswa mengharapkan media pembelajaran yang me miliki tampilan sederhana tapi menarik. Jangan menggunakan banyak animasi, karena akan mengganggu fokus dalam belajar. Karena hal yang dianggap paling sulit dalam pelajaran matematika yaitu penggunan bahasa yang sukar untuk dimengerti maka dari itu siswa menginginkan media dengan bahasa yang mudah dimengerti dan penjelasan secara mendetail. Maka dipilih lah Videoscribe Sparkol dikarenakan sangat mudah digunakan, powerfull dan usable siapapun dapat membuat video menggunakan Videoscribe Sparkol. Dalam pengembangan media pembelajaran dengan Videoscribe Sparkol ini tidak memerlukan keahlian khusus untuk menggambar. Maka dari itu pembuaatan media pembelajaran menggunakan Videoscribe Sparkol akan mudah dilakukan oleh semua kalangan.

\section{Design (Perencanaan)}

Langkah-langkah dalam perencanaan produk ialah menentukan tujuan yang akan dicapai siswa melalui penggunaan media, melakukan tinjauan materi pada pokok bahasan kekongruenan dan kesebangunan, menentukan aplikasi dan membuat rancangan desain media pembelajaran. Adapun rincian untuk masing-masing langkah adalah sebagai berikut.

a. Tujuan pembelajaran dirumuskan dalam penggunaan media adalah untuk mempermudah siswa dalam memahami materi kekongruenan dan kesebangunan, menambah daya tarik siswa dalam mempelajari materi kekongruenan dan kesebangunan, serta membuat media yang dapat dilihat kapan dan dimana saja.

b. Tinjauan materi dilakukan untuk menentukan materi yang akan dijadikan bahan dalam pembuatan media dan menyiapkan gambar-gambar pendukung yang akan dimasukkan dalam media sesuai dengan analisis kebutuhan.

c. Peralatan yang digunakan dalam pembuatan media pembelajaran video ini ialah laptop, microsoft word, adobe illustator, adobe premier dan videoscribe sparkol. Microsoft word digunakan untuk membuat materi, adobe ilustator digunakan untuk mendesain gambar meliputi pembuatan background, gambar ilustrasi, maupun teks yang sesuai dengan naskah materi yang dijadikan gambar dengan format png. Adobe premier digunakan untuk penyuntingan gambar (editing), pemaduan gambar dengan suara dan musik (mixing), dan kegiatan pengisian suara (dubbing). Sedangkan aplikasi videoscribe sparkol digunakan untuk penyusunan asset yang sudah dibuat di adobe illustator sesuai dengan rancangan dan susunan naskah yang dibuat.

d. Rancangan media pembelajaran yang dikembangkan berisi gambar-gambar materi dan latihan soal. Materi dibuat terpisah menggunakan adobe ilustator karna videoscribe sparkol tidak bisa membuat text panjang dan terurut rapih. 
Jurnal Lebesgue : Jurnal Ilmiah Pendidikan Matematika, Matematika dan Statistika

Ardistya Puspita Sari, Indra Martha Rusmana

Volume 2, No. 1, April 2021 hal.112-120

DOI Artikel : 10.46306/lb.v2i1.29

\section{Development (Pengembangan)}

a. Desain Awal Produk

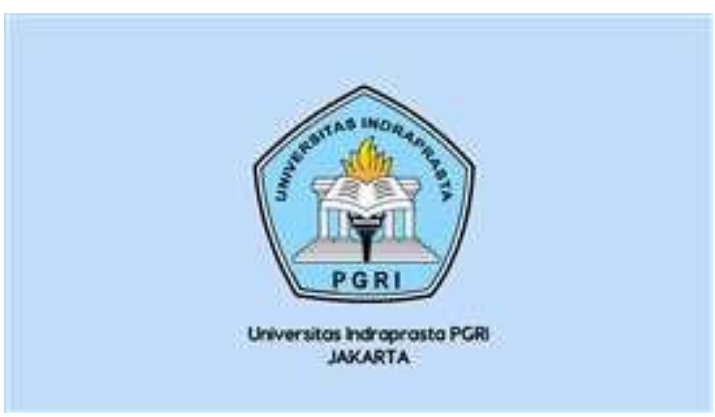

Gambar 1. Tampilan Awal

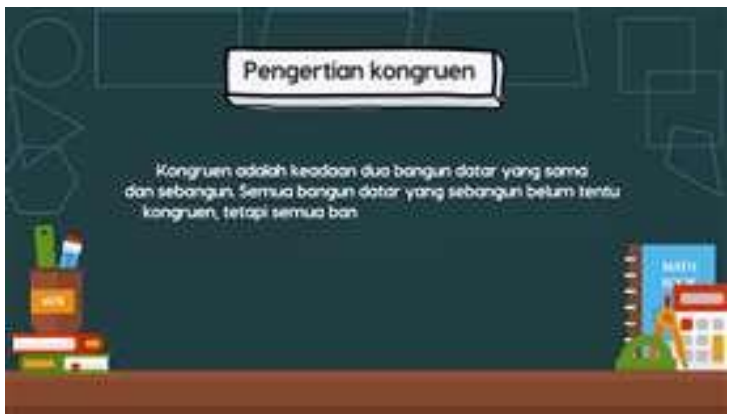

Gambar 3. Tampilan Materi

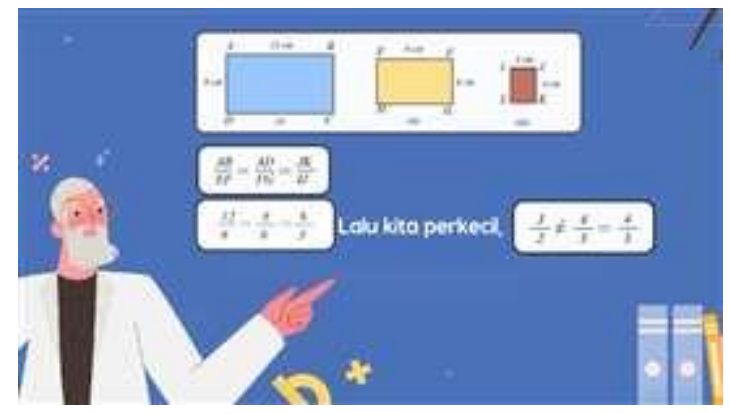

Gambar 5. Tampilan Pembahasan Soal

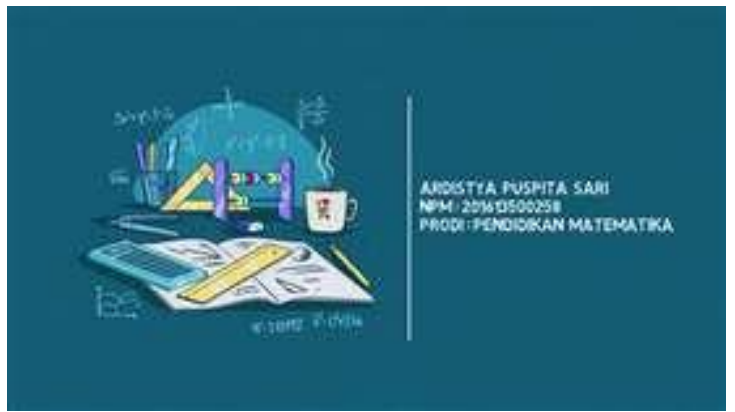

Gambar 2. Tampilan Profil Pengembang

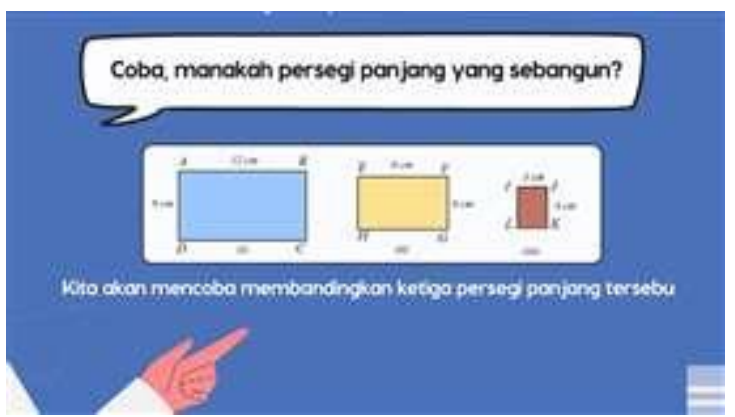

Gambar 4. Tampilan Contoh Soal 
Jurnal Lebesgue : Jurnal Ilmiah Pendidikan Matematika, Matematika dan Statistika

Ardistya Puspita Sari, Indra Martha Rusmana

Volume 2, No. 1, April 2021 hal.112-120

DOI Artikel : 10.46306/lb.v2i1.29

\section{b. Validasi Ahli Media, Ahli Materi dan Ahli Bahasa}

Validasi dilakukan agar mendapatkan kelayakan media untuk digunakan dalam kegiatan uji coba. Selain melakukan penilaian media dari ahli media, ahli materi dan ahli bahasa juga memberikan kritik dan saran guna perbaikan media pembelajaran. Hasil penilaian serta saran ahli digunakan sebagai dasar dalam merevisi produk awal sebelum diuji lapangan. Berikut disajikan hasil validasi ahli media, ahli materi, dan ahli bahasa.

Tabel 6. Rata-Rata Hasil Validasi Ahli Media

\begin{tabular}{ccc}
\hline Aspek & Rata-rata & Kriteria \\
\hline Media & 4,0 & Baik \\
\hline
\end{tabular}

Dari hasil data pada tabel di atas, maka hasil validasi ahli media dalam kategori "baik" dengan rata-rata penilaian terhadap media yaitu 4,0 .

Tabel 7. Rata-Rata Hasil Validasi Ahli Materi

\begin{tabular}{ccc}
\hline Aspek & Rata-rata & Kriteria \\
\hline Materi & 4,0 & Baik
\end{tabular}

Dari hasil data pada tabel di atas, maka hasil validasi ahli materi dalam kategori "sbaik" dengan rata-rata penilaian terhadap media yaitu 4,0.

Tabel 8. Rata-Rata Hasil Validasi Ahli Pengembangan

\begin{tabular}{ccc}
\hline Aspek & Rata-rata & Kriteria \\
\hline Materi & 4,25 & Sangat Baik
\end{tabular}

Dari hasil data pada tabel di atas, maka hasil validasi ahli bahasa dalam kategori "baik" dengan rata-rata penilaian terhadap media yaitu 4,25 .

\section{Implementation (Penerapan)}

Penerapan media pembelajaran ini hanya dibatasi sampai uji pakar yaitu ahli media, materi, dan bahasa. Setelah dinyatakan layak diproduksi oleh ahli media, ahli materi dan ahli bahasa, lalu media ini tidak diujikan pada uji lapangan pada kelompok kecil, dikarenakan kurangnya akses penelitian pada saat pandemi Covid 19 2020. Uji coba pakar pada media ini dilakukan dengan tujuan untuk mengetahui setiap detail kekurangan dan kelemahan dari media yang telah jadi, untuk melihat keefektifan media tersebut bila digunakan oleh sasaran didik yang dituju. 
Jurnal Lebesgue : Jurnal Ilmiah Pendidikan Matematika, Matematika dan Statistika

Ardistya Puspita Sari, Indra Martha Rusmana

Volume 2, No. 1, April 2021 hal.112-120

DOI Artikel : 10.46306/lb.v2i1.29

\section{Evaluation (Penilaian)}

Tahap terakhir adalah mengevaluasi media pembelajaran berbasis videoscribe yang telah dikembangkan. Tahap ini merupakan fase untuk mengetahui kelayakan produk yang dihasilkan dalam hal ini adalah media pembelajaran berbasis videoscribe sparkol pada mata pelajaran matematika pokok bahasan persamaan kekongruenan dan kesebangunan sekolah menengah pertama. Hal ini tidak bisa diterapkan karena adanya pandemi Covid-19 2020 yang mengharuskan siswa belajar dirumah. Kurangnya akses ke peserta didik untuk menerapkan tahap ini karena terkendala fasilitas dan pandemi.

\section{KESIMPULAN}

Berdasarkan hasil penelitian dan pengembangan, produk media pembelajaran berbasis videoscribe sparkol untuk pembelajaran matematika di SMP PGRI 2 Bogor maka dapat disimpulkan media pembelajaran berbasis videoscribe sparkol layak digunakan setelah melalui proses validasi dari ahli media, ahli materi dan ahli pengembangan. Hasil penilaian dari aspek media mendapat kriteria "baik", penilaian dari aspek materi mendapat kriteria "baik" dan penilaian dari aspek pengembangan mendapat kriteria "sangat baik".

\section{DAFTAR PUSTAKA}

Abdul Karim, Dini Savitri, \& Hasbullah. (2020). PENGEMBANGAN MEDIA PEMBELAJARAN MATEMATIKA BERBASIS ANDROID DI KELAS 4 SEKOLAH DASAR. Jurnal Lebesgue: Jurnal Ilmiah Pendidikan Matematika, Matematika Dan Statistika, 1(2), 63-75. doi:10.46306/lb.v1i2.17

Achdiyat, M., \& Utomo,R. 2017. Kecerdasan visual-spasial, kemampuan numerik, dan prestasi belajar matematika. Jurnal Formatif, 7(3), 234-245

Astuti, P., \& Febrian, F. (2019). Diseminasi Online Multimedia Pembelajaran Matematika yang Dikembangkan Menggunakan Videoscribe. Jurnal Anugerah, 1(1), 19-24. doi:10.31629/anugerah.v1i1.1650

Gusti, A. G. A., \& Indra Martha Rusmana. (2020). PENGEMBANGAN MEDIA LAGU RUMUS MATEMATIKA BERBASIS AUDIO PLAYER UNTUK KELAS VI SD/SEDERAJAT. Jurnal Lebesgue : Jurnal Ilmiah Pendidikan Matematika, Matematika Dan Statistika, 1(3), 140-152. doi:10.46306/lb.v1i3.28

Heriyati. 2017. Pengaruh minat dan motivasi belajar terhadap prestasi belajar matematika. Jurnal Formatif, 7(1), 22-32. 
Martha Rusmana, I., \& Mila Kurniawarsih. (2020). PENGEMBANGAN MEDIA PEMBELAJARAN KOMIK MATEMATIKA SISWA KELAS IV SEKOLAH DASAR BERBASIS BUDAYA. LEBESGUE, 1(1), 39-48. doi:10.46306/lb.v1i1.11

Nizam. 2016. Ringkasan Hasil-hasil Asesmen Belajar Dari Hasil UN, PISA, TIMSS, INAP. Puspendik.

Nurrohmah, F., Ganda Putra, F., \& Farida. (2018). Development of Sparkol VideoScribe Assisted Media. Formatif: Jurnal Ilmiah Pendidikan MIPA, 8(3), 233-250.

Rahmatika, D. F., \& Ratnasari, N. (2018). Media Pembelajaran Matematika Bilingual Berbasis Sparkol Videoscribe. Desimal: Jurnal Matematika, 1(3), 385-393. doi:10.24042/djm.v1i3.3061

Siswanto, D., Muhammad Sadar, \& Lasri Nijal. (2021). Bahan Ajar Menggunakan Sparkol Videoscribe Berbasis Multimedia untuk Technoprenuership Peningkatan Mutu Pembelajaran. J-COSCIS : Journal of Computer Science Community Service, 1(1), 56-62. doi:10.31849/jcoscis.v1i1.6187

Sugiyono. 2011. Metode Penelitian Kuantitatif, Kualitatif dan R \& D. Bandung : Alfabeta. 